\title{
MRI FINDINGS IN PATIENTS WITH LOW BACKACHE- OUR EXPERIENCE
}

\author{
Ashok Kumar Mandal ${ }^{1}$ Raunak Deo ${ }^{2}$
}

1Professor, Department of Radiodiagnosis, Patna Medical College and Hospital, Patna.

2Junior Resident, Department of Radiodiagnosis, Patna Medical College and Hospital, Patna.

ABSTRACT
BACKGROUND
Low backache is an increasingly common pathological condition that is becoming more frequent with increasing mean life
expectancy with high costs for society. It has many causes among which degenerative, neoplastic and traumatic causes stand out.
Most of the patients respond well to conservative therapy. Surgical treatment is reserved for patients who present symptoms after
implementation of conservative measures. Here is a series of 50 cases, which presented with complaint of low backache and
underwent MR scanning for identification of underlying pathology.
The objectives of this study is to elucidate different MRI findings in patients presenting with low backache.

\section{MATERIALS AND METHODS}

Patients having clinical symptom of low backache presented in Department of Radiology at Patna Medical College and Hospital, Patna, were included in the present study. On a random basis, 50 cases were included with chief complaint of low backache. All patients underwent routine MRI of lumbosacral spine.

\section{RESULTS}

Fifty patients were studied with low backache with a mean age of 48.86 yrs. \pm 15.6 (range 18 yrs. to 75 yrs.). In our study 34 patients who presented with low backache also showed degenerative changes on plain radiograph; however, 16 patients did not show any degeneration on plain radiograph. Out of 50 patients 30 patients (60\%) were diagnosed to have spinal canal stenosis, 45 patients (90\%) were diagnosed to have foraminal stenosis, either unilateral or bilateral; 41 patients (82\%) showed evidence of either disc bulge or disc herniation; 24 patients (48\%) presented with other findings, i.e. ligamentum flavum hypertrophy, ossification of posterior longitudinal ligament and posterior osteophytes on MRI; 2 patients (4\%) did not show any finding on MRI.

\section{CONCLUSION}

Low backache is an increasingly common pathological condition that is becoming more frequent with increasing mean life expectancy with high costs for society. It has many causes among which degenerative, neoplastic and traumatic causes stand out. Most of the patients respond well to conservative therapy. Surgical treatment is reserved for patients who present symptoms after implementation of conservative measures. Here is a series of 50 cases, which presented with complaint of low backache and underwent MR scanning for identification of underlying pathology.

\section{KEYWORDS}

Spine; Spinal Stenosis; Canal Stenosis; Disc Herniation; Disc Bulge; MRI Lumbar Spine.

HOW TO CITE THIS ARTICLE: Mandal AK, Deo R. MRI findings in patients with low backache- our experience. J. Evolution Med. Dent. Sci. 2017;6(54):4098-4100, DOI: 10.14260/Jemds/2017/885

\section{BACKGROUND}

Lumbar stenosis is defined as a pathological narrowing of the vertebral canal and/or intervertebral foramina that leads to compression of the thecal sac and/or the nerve roots. It may be confined just to one segment (two adjacent vertebrae and the intervertebral disc, joint facets and corresponding ligaments) or in situations of greater severity it may encompass two or more segments ${ }^{1}$ and present several aetiologies.

The presence of disc tissue extending beyond the edges of the ring apophyses throughout the circumference of the disc is called "bulging" and is not considered a form of herniation. It is the result of tears in the annulus fibrosus.

Financial or Other, Competing Interest: None.

Submission 21-05-2017, Peer Review 23-06-2017,

Acceptance 29-06-2017, Published 06-07-2017.

Corresponding Author:

Dr. Ashok Kumar Mandal,

Professor, Department of Radiodiagnosis,

Patna Medical College and Hospital,

Patna-800004, Bihar.

E-mail: ronniedb@gmail.com

DOI: $10.14260 /$ jemds $/ 2017 / 885$
Disc herniation is defined as a focal displacement of disc material $(<25 \%$ of the disc circumference) beyond the limits of the intervertebral disc space.

The main clinical manifestations are lumbalgia, generally associated with irradiation to the lower limbs and neurogenic claudication.

Radiological examinations, especially lumbar x-rays, Computed Tomography (CT) and Magnetic Resonance Imaging (MRI) are useful and essential tools for diagnosing and characterising lumbar stenosis.

\section{MATERIALS AND METHODS}

Patients having clinical symptom of low backache presented in Department of Radiology at Patna Medical College and Hospital, Patna from January 2017 to April 2017 were included in the present study. On the random basis, 50 cases are included with chief complaint of low backache. The inclusion criteria for analysis were patients who presented with low backache and were ready to undergo MR imaging. Patients who denied MR imaging were excluded from the study. All the patients underwent plain radiographs of lumbar spine, lateral and frontal views and were then 
followed up with MRI of lumbar spine. An informed consent was taken from all the patients, which mentioned the hazards of radiation received during plain radiograph scanning. All patients had consented for using the data for publications.

All patients underwent lateral plain radiograph of lumbar spine and routine MRI of lumbar spine. The criteria taken for lumbar canal stenosis was distance between middle of vertebral body and middle of basis of spinous process at the dural sac should be less than $10 \mathrm{~mm}$ on MRI axial sections of spine. Foraminal stenosis was diagnosed when the foraminal diameter on axial sections was less than $5 \mathrm{~mm} .^{1-3}$ Disc bulge was diagnosed when the edges of the disc tissue were extending beyond the ring apophysis. Disc herniation was diagnosed when a focal displacement of disc material $(<25 \%$ of the disc circumference) beyond the limits of the intervertebral disc space.4-7 Other findings taken into consideration were ligamentum flavum hypertrophy, ossification of posterior longitudinal ligament and posterior osteophytes. Ethical clearance was taken prior to the commencement of the study. The study was done to analyse different MRI findings in case of low backache.

\section{Statistical Analysis}

Microsoft Office 2010 was used for the statistical analysis. Mean and percentage were used to interpret the data.

\section{RESULTS}

Fifty patients were studied with low backache with a mean age of 48.86 yrs. \pm 15.6 (range 18 yrs. to 75 yrs.). In our study 34 patients who presented with low backache also showed degenerative changes on plain radiograph; however, 16 patients did not show any degeneration on plain radiograph. Out of 50 patients 30 patients $(60 \%)$ were diagnosed to have spinal canal stenosis, 45 patients $(90 \%)$ were diagnosed to have foraminal stenosis, either unilateral or bilateral; 41 patients (82\%) showed evidence of either disc bulge or disc herniation; 24 patients (48\%) presented with other findings, i.e. ligamentum flavum hypertrophy, ossification of posterior longitudinal ligament and posterior osteophytes on MRI; 2 patients (4\%) did not show any finding on MRI. Out of 45 patients with foraminal stenosis, 41 (91.1\%) were having disc bulge/herniation; however, 4 (8.9\%) patients did not have any disc bulge or herniation, but were associated with other findings. In the patients above the age group of 60 years, $100 \%$ of the patients had disc bulge/herniation. In our study of 50 patients, the main clinical symptom was low backache who then underwent MR imaging for lumbosacral spine.

\section{Demographics}

The age of the patients in our study ranged from 18 to 75 years. Out of 50 patients, 28 were females and 32 were males. All the patients hailed from Gangetic belt.

\section{Clinical Findings}

The clinical symptoms reported in our series are summarised in Table 1.

\begin{tabular}{|c|c|}
\hline Low backache & 50 cases \\
\hline Pain radiating to either of the two lower limbs & 8 cases \\
\hline Pain radiating to bilateral lower limb & 15 cases \\
\hline Claudication & 4 cases \\
\hline Tingling sensation in lower limbs & 3 cases \\
\hline Table 1. Clinical Symptoms \\
\hline
\end{tabular}

\begin{tabular}{|c|c|c|c|c|c|}
\hline $\begin{array}{c}\text { Age } \\
\text { Group } \\
\text { (Yrs.) }\end{array}$ & $\begin{array}{c}\text { No. of } \\
\text { Patients }\end{array}$ & $\begin{array}{c}\text { Patients } \\
\text { with Disc } \\
\text { Bulge/ } \\
\text { Herniation }\end{array}$ & $\begin{array}{c}\text { Patients } \\
\text { with } \\
\text { Foraminal } \\
\text { Stenosis }\end{array}$ & $\begin{array}{c}\text { Patients } \\
\text { with Canal } \\
\text { Stenosis }\end{array}$ & $\begin{array}{c}\text { Other } \\
\text { Findings }\end{array}$ \\
\hline $0-20$ & 3 & $1(2 \%)$ & $1(2 \%)$ & $1(2 \%)$ & $0(0 \%)$ \\
\hline $21-30$ & 6 & $3(6 \%)$ & $3(6 \%)$ & $0(0 \%)$ & $0(0 \%)$ \\
\hline $31-40$ & 8 & $7(14 \%)$ & $8(16 \%)$ & $6(12 \%)$ & $3(6 \%)$ \\
\hline $41-50$ & 9 & $8(16 \%)$ & $9(18 \%)$ & $4(8 \%)$ & $6(12 \%)$ \\
\hline $51-60$ & 11 & $9(18 \%)$ & $11(22 \%)$ & $8(16 \%)$ & $5(10 \%)$ \\
\hline $61-70$ & 10 & $10(20 \%)$ & $10(20 \%)$ & $8(16 \%)$ & $7(14 \%)$ \\
\hline $71-75$ & 3 & $3(6 \%)$ & $3(6 \%)$ & $3(6 \%)$ & $3(6 \%)$ \\
\hline Total & $\mathbf{5 0}$ & $\mathbf{4 1 ( 8 2 \% )}$ & $\mathbf{4 5} \mathbf{9 0 \% )}$ & $\mathbf{3 0}(\mathbf{6 0 \% )}$ & $\mathbf{2 4}(\mathbf{4 8 \% )}$ \\
\hline \multicolumn{5}{|c|}{ Table 2. MR Imaging Findings } \\
\hline
\end{tabular}

\section{DISCUSSION}

The lumbar canal stenosis is quite a common condition. Currently, its incidence is 1:1000 and has been increasing in recent years due to increased life expectancy.4-6 Conventionally, plain radiographs were used for its diagnosis and with advent of CT scan the diagnostic accuracy improved even further. In recent years, the introduction of MRI has made the diagnosis very accurate owing to the ability of MRI to visualise soft tissues, which are missed on CT scans.

The presence of disc tissue extending beyond the edges of the ring apophyses throughout the circumference of the disc is called "bulging" and is not considered a form of herniation. It is the result of tears in the annulus fibrosus. ${ }^{8-11}$

Asymmetric bulging of disc tissue greater than $25 \%$ of the disc circumference is often seen as an adaptation to adjacent deformity. ${ }^{8-11}$

Disc herniation is defined as a focal displacement of disc material $(<25 \%$ of the disc circumference) beyond the limits of the intervertebral disc space. A herniated disc can be contained (covered by outer annulus fibrosus) or uncontained. Disc herniations are contained if the displaced portion is covered by outer annulus fibres and/or the posterior longitudinal ligament.

The margins of the contained disc protrusions are smooth on imaging. Disc herniations are uncontained when there is no such covering. ${ }^{8-11}$

Protrusion indicates that the distance between the edges of the disc herniation is less than the distance between the edges of the base. ${ }^{8-11}$

Extrusion is present when the distance between the edges of the disc material is greater than the distance at the base..$^{8-11}$

Migration indicates displacement of disc material away from the site of extrusion, regardless of whether sequestrated or not.8-11 The term sequestration is used to indicate that the displaced disc material has lost continuity with the parent $\operatorname{disc}^{8-11}$

\section{CONCLUSION}

From our study, we can conclude that the patients presenting with low backache can have different findings on MRI. In our study, the patients who had lumbar canal stenosis also had other findings as well. Few patients only had foraminal stenosis; however, all the patients who had lumbar canal stenosis also had foraminal stenosis either unilateral or bilateral. Most of the patients who had canal stenosis or foraminal stenosis also had disc bulge/herniation. However, few patients with foraminal stenosis and canal stenosis had no disc bulge or herniation, but had ligamentum flavum hypertrophy, ossification of posterior longitudinal ligament 
or posterior osteophytes. In our study, the findings were more frequent in higher age groups.

\section{REFERENCES}

[1] Hamanishi C, Matukura N, Fujita M, et al. Crosssectional area of the stenotic lumbar dural tube measured from the transverse views of magnetic resonance imaging. J Spinal Disord 1994;7(5):388-93.

[2] Herzog RJ, Kaiser JA, Saal JA, et al. The importance of posterior epidural fat pad in lumbar central canal stenosis. Spine (Phila Pa 1976) 1991;16(6 Suppl):S227-33.

[3] Jönsson B, Annertz M, Sjöberg C, et al. A prospective and consecutive study of surgically treated lumbar spinal stenosis. Part I: clinical features related to radiographic findings. Spine (Phila Pa 1976) 1997;22(24):2932-7.

[4] Grenier N, Kressel HY, Schiebler ML, et al. Normal and degenerative posterior spinal structures: MR imaging. Radiology 1987;165(2):517-25.

[5] Lee CK, Rauschning W, Glenn W. Lateral lumbar spinal canal stenosis: classification, pathologic anatomy and surgical decompression. Spine (Phila Pa 1976) 1988; 13(3):313-20.
[6] Strojnik T. Measurement of the lateral recess angle as a possible alternative for evaluation of the lateral recess stenosis on a CT scan. Wien Klin Wochenschr 2001;113(Suppl 3):53-8.

[7] Hall S, Bartleson JD, Onofrio BM, et al. Lumbar spinal stenosis. Clinical features, diagnostic procedures, and results of surgical treatment in 68 patients. Ann Intern Med 1985;103(2):271-5.

[8] Teufack SG, Singh H, Harrop J, et al. Dorsal epidural intervertebral disk herniation with atypical radiographic findings: case report and literature review. J Spinal Cord Med 2010;33(3):268-71.

[9] Döso-lu M, Is M, Gezen F, et al. Posterior epidural migration of a lumbar disc fragment causing cauda equina syndrome: case report and review of the relevant literature. Eur Spine J 2001;10(4):348-51.

[10] Fardon DF, Milette PC. Nomenclature and classification of lumbar disc pathology. Recommendations of the combined task forces of the North American spine society, American society of spine radiology, and American society of neuroradiology. Spine 2001;26(5):E93-113.

[11] Kraemer J. Intervertebral disk diseases: causes, diagnosis, treatment, and prophylaxis. $3^{\text {rd }}$ edn. Stuttgart, Germany: Thieme 2009. 